\title{
Comparison of toxicant load from waterpipe and cigarette tobacco smoking among young adults in the USA
}

\author{
Brian A Primack, 1,2,3,4 Ariel Shensa, 1,2 Jaime E Sidani, 1,2 Megan C Tulikangas, 1,5 \\ Mark S Roberts, 2,5,6 Jason B Colditz, 1,2 Maria K Mor, ${ }_{1}^{6}$ A Everette James, 1,5,7 \\ Michael J Fine ${ }^{2,6}$
}

\begin{abstract}
- Additional material is published online only. To view please visit the journal online (http://dx.doi.org/10.1136/
\end{abstract} tobaccocontrol-2017-054226)

${ }^{1}$ Center for Research on Media, Technology, and Health, University of Pittsburgh, Pittsburgh, Pennsylvania, USA ${ }^{2}$ Division of General Internal Medicine, Department of Medicine, University of Pittsburgh, Pittsburgh Pennsylvania, USA ${ }^{3}$ Division of Adolescent Medicine, Department of Pediatrics, University of Pittsburgh School of Medicine, Pittsburgh, Pennsylvania, USA ${ }^{4}$ Honors College, University of Pittsburgh, Pittsburgh, PA, USA ${ }^{5}$ Health Policy Institute, University of Pittsburgh, Pittsburgh, Pennsylvania, USA ${ }^{6}$ Center for Health Equity and Research Promotion, VA Pittsburgh Healthcare System, Pittsburgh, Pennsylvania, USA ${ }^{7}$ Department of Health Policy and Management, Graduate School of Public Health, University of Pittsburgh, Pittsburgh, Pennsylvania, USA

Correspondence to Dr Brian A Primack, Department of Medicine, University of Pittsburgh School of Medicine, Pittsburgh, PA 15213, USA; bprimack@pitt.edu

Received 23 December 2017 Revised 8 March 2018 Accepted 21 March 2018 Published Online First 16 May 2018

Check for updates

To cite: Primack BA Shensa A, Sidani JE, et al. Tob Control 2019;28:60-66.

\begin{abstract}
Objectives To form population-level comparisons of total smoke volume, tar, carbon monoxide and nicotine consumed from waterpipe tobacco smoking (WTS) and cigarette smoking using data from a nationally representative sample of smokers and non-smokers aged 18-30 years.

Methods In March and April 2013, we surveyed a nationally representative sample of 3254 US young adults to assess the frequency and volume of WTS and cigarette smoking. We used Monte Carlo analyses with 5000 repetitions to estimate the proportions of toxicants originating from WTS and cigarette smoking. Analyses incorporated survey weights and used recent metaanalytic data to estimate toxicant exposures associated with WTS and cigarette smoking.
\end{abstract}

Results Compared with the additive estimates of WTS and cigarette smoking combined, $54.9 \%(95 \% \mathrm{Cl} 37.5 \%$ to $72.2 \%$ ) of smoke volume was attributed to WTS. The proportions of tar attributable to WTS was $20.8 \%$ (95\% Cl $6.5 \%$ to $35.2 \%)$, carbon monoxide $10.3 \%(95 \% \mathrm{Cl}$ $3.3 \%$ to $17.3 \%)$ and nicotine $2.4 \%(95 \% \mathrm{Cl} 0.9 \%$ to $3.8 \%)$.

Conclusions WTS accounted for over half of the tobacco smoke volume consumed among young US adult waterpipe and cigarette smokers. Toxicant exposures to tar, carbon monoxide and nicotine were lower, but still substantial, for WTS alone compared with WTS and cigarette smoking. Public health and policy interventions to reduce harm from tobacco smoking in young US adults should explicitly address WTS toxicant exposures.

\section{INTRODUCTION}

Waterpipe tobacco smoking (WTS) is an ancient practice rooted in the Indian subcontinent and the Eastern Mediterranean Region, ${ }^{1}{ }^{2}$ but it has rapidly spread to the USA and other Western countries. ${ }^{34}$ Many factors contribute to this trend, including compelling flavourings, ${ }^{2}$ misperceptions about safety, ${ }^{5}$ social acceptability ${ }^{67}$ and permissive policies. ${ }^{89}$

Known colloquially as 'hookah smoking', WTS is particularly popular among young adults. Approximately $5 \%-10 \%$ of US young adults are current waterpipe tobacco users (having taken at least one puff in the past 30 days), ${ }^{10} 1120 \%-30 \%$ are pastyear users (having taken at least one puff in the past year) ${ }^{12} 13$ and $25 \%-40 \%{ }^{14} 15$ report lifetime use (having taken at least one puff ever). In longitudinal studies, 13\%-23\% of first and second year college students report initiating WTS ${ }^{1617}$; however, young adults not in college also report substantial use. ${ }^{1418}$

WTS is described as less irritating compared with cigarette smoking. ${ }^{19}$ However, compared with a single cigarette, one 45 min WTS session is associated with exposure to higher levels of toxicants such as tar, carbon monoxide and nicotine. ${ }^{2021}$ Furthermore, a typical 1 hour WTS session results in approximately 100-200 times the smoke volume inhaled from a single cigarette. ${ }^{22}$ Additionally, WTS has been associated with negative health outcomes, such as respiratory and cardiac disease ${ }^{23-27}$ and dependence. ${ }^{28}$

The majority of waterpipe users in the USA who report current WTS are not daily users. ${ }^{15}$ 29-31 Whereas a heavy cigarette smoker may consume 20 cigarettes per day, heavy WTS may involve 2-3 sessions per day. ${ }^{32} 33$ Compared with cigarette smoking, WTS experimentation seems less likely to result in long-term, regular use. ${ }^{3435}$ Therefore, WTS may add only a marginal amount to the overall population-level toxicant load thought to be primarily from cigarette smoking. If this is the case, the thrust of public health and policy-related interventions should remain squarely on cigarette smoking. In contrast, if the toxicant load from WTS is detectable, then future tobacco reduction interventions should be modified accordingly.

A prior study used a cross-sectional, population-level model to investigate toxicant exposure among adolescents in the Eastern Mediterranean Region. ${ }^{33}$ We sought to extend this research by comparing the smoke volume, tar, carbon monoxide and nicotine consumed from WTS and cigarette smoking among young adults in the US population. To quantify relevant toxicant exposures, we leveraged nationally representative self-reported tobacco use data and recent meta-analytic estimates of WTS and cigarette smoking toxicant exposures. ${ }^{20}$

\section{METHODS}

\section{Participants and procedures}

Participants were recruited with the assistance of a survey research company, Growth from Knowledge (GfK). ${ }^{36}$ GfK developed its panel using a combination of random digit dialling and address-based sampling, increasing its sampling frame to an estimated $97 \%$ of US households. Members of this panel of 50000 individuals over the age of 18 years are randomly selected to participate in online 
surveys. Surveys are completed on the participants' personal computers, which are provided, along with internet access, by GfK if needed. Participants maintain a limited tenure on the panel in order to reduce the risk of becoming jaded to surveys.

We commissioned GfK to survey approximately 3000 adults aged 18-30 years old. The online survey was sent to a randomly selected sample of panel members in March 2013 and was active for a 1-month period. Eligibility criteria included status as a non-institutionalised, US adult aged 18-30 years. Smoking status was not considered for participant eligibility. Participants received $\$ 10$ for survey completion. This study was granted a Certificate of Confidentiality from the National Institutes of Health.

\section{Measures}

Waterpipe tobacco smoking

All items asking about WTS referred to a waterpipe as a 'hookah', the term most commonly used among US young adults. Instructions preceding all WTS use items instructed the respondents to answer only about tobacco (with the word 'tobacco' underlined). To estimate WTS over the past month, we first asked participants to quantify how many of the past 30 days they smoked tobacco from a hookah. For those responding affirmatively to having smoked tobacco from a hookah in the past 30 days, we asked them to estimate how many times they smoked from a hookah on the last day they smoked. Finally, we asked them to estimate how many 'heads' (also known as 'bowls') of tobacco they consumed during their most recent WTS session. These three pieces of data were multiplied to generate an estimated number of bowls consumed over the past month. Additionally, we calculated the proportion of dual users-individuals who had engaged in both WTS and cigarette smoking-in the past 30 days.

\section{Cigarette smoking}

We asked participants to estimate how many of the past 30 days they smoked cigarettes. Participants who had smoked at least once in the past 30 days were asked how many cigarettes they smoked on the last day they smoked. Similar to other research, ${ }^{33}$ several assumptions about cigarette smoking behaviour were made, including that participants did not share cigarettes, that participants smoked 'regular' cigarettes that were not considered 'light' or 'unfiltered' and that participants smoked the entire cigarette. We multiplied the number of days smoked times the number of cigarettes smoked each day to estimate the total number of cigarettes smoked over the past 30 days.

Data quality checks screened for individuals with results that were not feasible in terms of number of hookah bowls and/or cigarettes in a given day. For example, we lowered individuals' last-day estimate to 18 for WTS, which we defined a priori as the maximum feasible number of bowls in 1 day. We arrived at this number-conservatively assuming participants had a maximum of 18 waking hours-estimating a smoking rate of 1 bowl per hour. Because the largest reported daily cigarette value was 50, no cigarette data were deemed unfeasible.

\section{Toxicant exposure from waterpipe and cigarette tobacco smoking}

To estimate population-level toxicant exposures from WTS and cigarette smoking, we used point estimates and 95\% CIs derived from a meta-analysis published in $2016 .{ }^{20}$ This report pooled data from 17 studies culled from seven biomedical bibliographic databases for controlled laboratory or natural environment studies designed to mimic human tobacco consumption. All included studies quantified the mainstream smoke of a single cigarette and/or single WTS bowl for smoke volume, tar, carbon monoxide and nicotine, measured in litres for smoke volume and milligrams for the others. While smoke volume is not a toxicant itself, it does represent a relevant measurement of exposure to toxicants that can be used to compare a typical WTS and cigarette smoking session. For WTS, the pooled estimates and 95\% CIs of smoke volume is 74.1 (38.2 to 110.0 ), $\operatorname{tar} 619.0$ (244.0 to 994.0), carbon monoxide 192.0 (77.5 to 307.0) and nicotine 4.1 (2.7 to 5.4 ). For a cigarette, smoke volume is 0.6 (0.5 to 0.7 ), $\operatorname{tar} 24.5$ (15.5 to 33.6), carbon monoxide 17.7 (16.6 to 19.9 ) and nicotine 1.8 (1.3 to 2.3 ).

\section{Methods of analysis}

Using our primary data on cigarette and waterpipe smoking collected in March and April 2013, and survey weights provided by GfK, we calculated the number of cigarettes and the number of waterpipe bowls consumed by the entire population. Survey weights were constructed based on demographic benchmark distributions and included sex, age, race/ethnicity, education, household income, census region, metropolitan area and internet access before the study began. These weights were applied to adjust for any non-response, non-coverage and undersampling or oversampling due to study design. ${ }^{36}$ Because these values were based on a sample of 3254 individuals and not on the entire population, we also calculated the SE of the mean (SEM) around the mean values for cigarettes and waterpipe bowls consumed to include in Monte Carlo analyses.

We conducted four Monte Carlo analyses, each of which had 5000 repetitions. There was one analysis for each of the outcomes of interest (smoke volume, tar, carbon monoxide and nicotine). Each analysis generated an estimated total volume of each outcome of interest from waterpipes and from cigarettes. The waterpipe estimate was generated by multiplying the number of waterpipes smoked (varied by the SEM) by the average toxicant per waterpipe bowl according to the meta-analytic data (varied by the SD from the meta-analysis ${ }^{20}$ ). Similarly, the cigarette estimate was generated by multiplying the number of cigarettes smoked (varied by the SEM) by the average toxicant per cigarette according to the meta-analytic data (varied by the SD from the meta-analysis ${ }^{20}$ ). We then divided total waterpipe toxicant by the sum of total waterpipe and total cigarette toxicant for each repetition to estimate the proportion attributable to waterpipe. We used the resulting set of 5000 estimated proportions to generate a mean proportion for waterpipes and its $95 \% \mathrm{CI}$.

We then conducted four sets of subgroup analyses to examine if any one group bears a greater toxicant burden. First, we stratified participants by single versus dual use and conducted the Monte Carlo analyses using adjusted means and SEMs for each group. Single users reported having engaged in either WTS or cigarette smoking in the past 30 days, whereas dual users reported engaging in both. We chose these analyses because total toxicant exposure derived from dual users has been found to be substantially greater than from single users. ${ }^{33}$ Next, we stratified participants by sex (female or male), race/ethnicity (White or non-Hispanic/other), and household income (low or medium/ high) and repeated the analyses.

Finally, we conducted four sets of sensitivity analyses to address areas of potential bias and examine the robustness of our results. Using the entire sample of participants, we varied the parameter of bowls consumed in the past 30 days-increasing and decreasing it by $10 \%$ and $20 \%$. We chose these parameters 
Table 1 Comparison of weighted baseline respondent sociodemographic characteristics stratified by waterpipe and cigarette tobacco smoking in the past 30 days*

\begin{tabular}{|c|c|c|c|c|c|}
\hline \multirow[b]{2}{*}{ Sociodemographic characteristics } & \multirow[b]{2}{*}{ Proportion of sample (\%) } & \multicolumn{2}{|c|}{ Waterpipe smoking within 30 days (\%) } & \multicolumn{2}{|c|}{ Cigarette smoking within 30 days (\%) } \\
\hline & & Yes $(n=210)$ & No $(n=3044)$ & Yes $(n=762)$ & No $(n=2492)$ \\
\hline Sex, female & 51.0 & 51.2 & 51.0 & 50.7 & 51.1 \\
\hline $18-20$ & 21.7 & 36.6 & 20.9 & 16.8 & 23.2 \\
\hline $21-23$ & 23.9 & 26.1 & 23.7 & 23.0 & 24.1 \\
\hline $24-26$ & 22.8 & 24.9 & 22.7 & 27.8 & 21.3 \\
\hline \multicolumn{6}{|l|}{ Race and ethnicity§ } \\
\hline White, non-Hispanic & 57.5 & 55.1 & 57.6 & 58.2 & 57.3 \\
\hline Black, non-Hispanic & 13.2 & 9.6 & 13.4 & 13.9 & 13.0 \\
\hline Hispanic & 20.3 & 26.4 & 20.0 & 22.1 & 19.8 \\
\hline Other, non-Hispanic & 9.0 & 8.9 & 9.0 & 5.8 & 10.0 \\
\hline \multicolumn{6}{|l|}{ Educational level‡ } \\
\hline \multicolumn{6}{|l|}{ Household incomeł } \\
\hline Under $\$ 30000$ & 19.5 & 23.6 & 19.3 & 27.8 & 17.0 \\
\hline$\$ 30000-\$ 74999$ & 33.6 & 34.9 & 33.5 & 37.4 & 32.4 \\
\hline$\$ 75000$ and above & 46.9 & 41.5 & 47.2 & 34.8 & 50.6 \\
\hline
\end{tabular}

*Percentage totals may not equal 100 due to rounding. For more information on unweighted data, see table 1 in the online supplementary appendix.

tIndicates a significant difference between respondents who smoked waterpipe within the past 30 days and those who did not. Significance determined by $\chi^{2}$ tests and a $p$ value $<0.05$.

fIndicates a significant difference between respondents who smoked a cigarette(s) within the past 30 days and those who did not. Significance determined by $\chi^{2}$ tests and a $p$ value $<0.05$.

§Race and ethnic groups were self-reported; the category 'Other, non-Hispanic' includes those who self-identified as multiracial.

to account for potential variation in several variables that may affect toxicant exposure but were not assessed in this study (table 4). For example, we chose to use a standard session length of 45-60 min because of prior data suggesting these averages. $^{37-39}$ This sensitivity analysis accounts for potential variations in session lengths, ranging from a few puffs over short sessions to longer sessions in lounges or during holidays, as well as the number, type and size of charcoal used during the WTS session. ${ }^{33} 40-42$ Furthermore, this sensitivity analysis allowed us to account for toxicant exposure for individuals who participated in WTS alone-or in a group-a factor that has shown differential results in recent research depending on the toxicant measured. ${ }^{40}$

Descriptive analyses were conducted using Stata Statistical Software, (StataCorp) and Monte Carlo analyses were conducted using Microsoft Excel. ${ }^{43}$

\section{RESULTS}

\section{Survey sample}

The survey was sent to a random sample of panel participants until 3468 individuals accepted the invitation, because it was estimated that this number of eligible individuals would result in our goal of at least 3000 completions. The completion rate was stronger than hoped, with 3254 (94\%) successfully completing the survey within the allotted time frame. Our unweighted sample was $63.0 \%$ female, $10.1 \%$ African-American and $17.5 \%$ Hispanic/Latino. Mean age was 23.8 years $(\mathrm{SD}=3.4)$. Other demographic details, including a description of the weighted sample, are provided in online supplementary appendix and table 1 .

\section{WTS and cigarette smoking}

When incorporating survey weights, WTS was reported by $5.1 \%$ of participants in the past 30 days. The majority of those participants reported having smoked one session on the last day they smoked tobacco from a waterpipe and one bowl at the most recent session $(85.5 \%$ and $69.8 \%$, respectively). Results from 16 individuals were deemed as unfeasible in terms of reported WTS. For example, after multiplying the number of sessions by the number of bowls, one individual claimed to have smoked 32 bowls on the most recent smoking day. Approximately 3\% of the sample reported dual use of both WTS and cigarettes in the past 30 days. Among all participants, the mean number of bowls smoked in the past 30 days was 0.43 , and among dual users, the mean was 7.3.

Cigarette smoking was reported by $23.4 \%$ of participants in the past 30 days. About half $(53.5 \%)$ of these individuals reported smoking on more than 20 of the past 30 days. Almost half $(45.4 \%)$ of those who had smoked in the past 30 days reported smoking three or fewer cigarettes on each day that they smoked, and about a quarter $(27.7 \%)$ of participants reported smoking 10 or more cigarettes on each day that they smoked. Among all participants, the mean number of cigarettes smoked in the past 30 days was 41.2 , and among dual users, the mean was 111.7. Complete estimates of mean WTS bowls and cigarettes smoked in the past 30 days by sociodemographic characteristic are reported in table 2.

\section{Toxicant exposure}

Based on Monte Carlo analyses using weighted sample data, the mean past 30 day volume of smoke, tar, carbon monoxide and 
Table 2 Total waterpipe and cigarette tobacco smoking in the past 30 days according to sociodemographic characteristics*

\begin{tabular}{|c|c|c|c|}
\hline $\begin{array}{l}\text { Sociodemographic } \\
\text { characteristics }\end{array}$ & $\begin{array}{l}\text { Percentage } \\
\text { of sample }\end{array}$ & $\begin{array}{l}\text { Mean waterpipe } \\
\text { bowls smoked in } \\
\text { the past } 30 \text { days }\end{array}$ & $\begin{array}{l}\text { Mean cigarettes } \\
\text { smoked in the } \\
\text { past } 30 \text { days }\end{array}$ \\
\hline All participants & 100.0 & 0.43 & 41.22 \\
\hline Dual users† & 2.7 & 7.26 & 111.74 \\
\hline \multicolumn{4}{|l|}{ Sex } \\
\hline Female & 51.0 & 0.38 & 37.55 \\
\hline Male & 49.0 & 0.49 & 45.04 \\
\hline \multicolumn{4}{|l|}{ Age (years) $\ddagger \S$} \\
\hline $18-20$ & 21.7 & 0.59 & 19.39 \\
\hline $21-23$ & 23.9 & 0.78 & 33.43 \\
\hline $24-26$ & 22.8 & 0.43 & 52.64 \\
\hline $27-30$ & 31.7 & 0.07 & 53.82 \\
\hline \multicolumn{4}{|l|}{ Race and ethnicity $\neq \mathbb{9}$} \\
\hline White, non-Hispanic & 57.5 & 0.37 & 46.94 \\
\hline Black, non-Hispanic & 13.2 & 0.08 & 35.94 \\
\hline Hispanic & 20.3 & 0.48 & 35.00 \\
\hline Other, non-Hispanic & 9.0 & 1.21 & 26.45 \\
\hline \multicolumn{4}{|l|}{ Educational levelÆ§ } \\
\hline High school or less & 39.4 & 0.49 & 65.23 \\
\hline Some college & 38.5 & 0.58 & 36.49 \\
\hline $\begin{array}{l}\text { Bachelor's degree or } \\
\text { higher }\end{array}$ & 22.2 & 0.08 & 6.74 \\
\hline \multicolumn{4}{|l|}{ Household income§ } \\
\hline Under $\$ 30000$ & 19.5 & 0.56 & 73.88 \\
\hline$\$ 30000-\$ 74999$ & 33.6 & 0.37 & 40.40 \\
\hline$\$ 75000$ and above & 46.9 & 0.43 & 28.20 \\
\hline
\end{tabular}

*Data represent weighted estimates.

tDual users are defined as individuals who engaged in both WTS and cigarette smoking in the past 30 days.

¥Indicates a significant association between the sociodemographic variable and mean waterpipe bowls smoked in the past year. Significance determined by regression analyses and a $\mathrm{p}$ value $<0.05$.

§Indicates a significant association between the sociodemographic variable and mean cigarettes smoked in the past year. Significance determined by regression analyses and a $p$ value $<0.05$.

IRace and ethnic groups were self-reported; the category 'Other, non-Hispanic' includes multiracial.

WTS, waterpipe tobacco smoking.

nicotine originating from WTS was $31.8 \mathrm{~L}, 264.8 \mathrm{mg}, 84.5 \mathrm{mg}$ and $1.8 \mathrm{mg}$, respectively. For cigarettes, the volume of smoke, tar, carbon monoxide and nicotine was $24.7 \mathrm{~L}, 1007.1 \mathrm{mg}$, $727.9 \mathrm{mg}$ and $74.6 \mathrm{mg}$, respectively. The proportion of smoke volume originating from waterpipes versus the additive exposure from waterpipes plus cigarettes was $54.9 \%$ (95\% CI $37.5 \%$ to $72.2 \%)$. The proportions of tar, carbon monoxide and nicotine originating from waterpipes versus waterpipes plus cigarettes were $20.8 \%$ (95\% CI $6.5 \%$ to $35.2 \%$ ), $10.3 \%$ (95\% CI $3.3 \%$ to $17.3 \%)$ and $2.4 \%$ (95\% CI $0.9 \%$ to $3.8 \%$ ), respectively (table 3 ).

Among dual users, the proportions of tar, carbon monoxide and nicotine originating from waterpipes versus both waterpipes and cigarettes were $88.1 \%$ (95\% CI $79.2 \%$ to $97.0 \%$ ), $60.7 \%$ (95\% CI $37.4 \%$ to $84.0 \%$ ), $13.5 \%$ (95\% CI $4.6 \%$ to $22.3 \%$ ) and $40.4 \%$ (95\% CI $19.3 \%$ to $61.5 \%$ ), respectively, whereas among single users of either WTS or cigarettes, the respective proportions attributable to WTS were $41.2 \%$ (95\% CI $19.9 \%$ to 62.4\%), $13.5 \%$ (95\% CI $1.7 \%$ to $25.3 \%$ ), $1.4 \%$ (95\% CI $0.3 \%$ to $2.6 \%)$ and $6.2 \%(95 \%$ CI $0.8 \%$ to $11.7 \%)$. The proportions of toxicant exposures attributable to WTS were similar among females and males, white, non-Hispanic and individuals of other race and ethnicity, as well as by household income (table 4).

\section{Sensitivity analyses}

When we varied the average number of bowls consumed over the past 30 days by increases and decreases of $10 \%$ and $20 \%$, the proportion originating from waterpipes versus both waterpipes and cigarettes ranged from $51.1 \%$ to $60.5 \%$ for smoke volume, $18.6 \%$ to $25.1 \%$ for tar, $2.0 \%$ to $3.0 \%$ for nicotine and $8.8 \%$ to $12.4 \%$ for carbon monoxide. Complete data from sensitivity analyses is presented in table 4 .

\section{DISCUSSION}

Combining self-reported frequency and quantity of tobacco consumption information with meta-analytic estimates of the toxicant loads associated with two common types of tobacco smoking, we found WTS was responsible for $54.9 \%$ of smoke, $20.9 \%$ of tar, $10.3 \%$ of carbon monoxide and $2.4 \%$ of nicotine consumed in the past 30 days by a nationally representative cohort of young adults aged 18-30 years.

Our findings are consistent with those of a prior model developed by Jawad and Roderick in several ways. ${ }^{33}$ For example, we found that dual users of both WTS and cigarettes (3\% of our sample) contribute substantially more to total toxicant load than single users. This is consistent with Jawad and Roderick's findings that demonstrated that dual users smoke more frequently and intensely than single users. Additionally, we estimated cigarette use based on the assumption that participants smoked the entire cigarette and did not share it. Similarly, Jawad and Roderick based their model on the assumptions that all cigarette users smoked with the same intensity and duration and did not share their cigarettes with others. However, our findings also differ and extend those of this prior model. For example, we modelled toxicant exposure among US young adults aged 18-30 years. Jawad and Roderick focused on EMR adolescents aged 12-17 years. Furthermore, we sought to provide a starting point for modelling population-level toxicant exposure, as many parameters involved in WTS are still unknown among US populations. Jawad and Roderick, given more extensive research on

Table 3 Average past 30-day estimates of toxicant exposures attributable to waterpipe tobacco smoking (WTS) and cigarette smoking among US adults aged $18-30$ years

\begin{tabular}{|c|c|c|c|}
\hline Toxicant & WTS* & Cigarette smoking* & Proportion attributable to WTSt \\
\hline Smoke volume, L & $31.78(10.54)$ & $24.67(2.50)$ & 54.87 (37.54 to 72.20$)$ \\
\hline Tar, mg & $264.83(102.71)$ & $1007.13(199.52)$ & 20.83 (6.47 to 35.18$)$ \\
\hline Carbon monoxide, mg & $84.54(31.56)$ & $727.85(61.66)$ & 10.33 (3.34 to 17.33$)$ \\
\hline Nicotine, mg & $1.77(0.48)$ & $74.58(11.54)$ & $2.36(0.91$ to 3.82$)$ \\
\hline
\end{tabular}

${ }^{*}$ Means and SD derived from Monte Carlo analyses with 5000 repetitions.

†95\% Cls constructed using SD from 5000 repetitions. 
Table 4 Proportion of past 30-day toxicant exposures attributed to waterpipe tobacco smoking varied by population and bowl parameters

\begin{tabular}{|c|c|c|c|c|}
\hline Parameter & Smoke volume* & Tar* & Carbon monoxide* & Nicotine* \\
\hline \multicolumn{5}{|l|}{ Population } \\
\hline All & 54.9 (37.5 to 72.2$)$ & 20.8 (6.5 to 35.2 ) & $10.3(3.3$ to 17.3$)$ & 2.4 (0.9 to 3.8$)$ \\
\hline Single userst & 41.2 (19.9 to 62.4$)$ & 13.5 (1.7 to 25.3$)$ & 6.2 (0.8 to 11.7$)$ & 1.4 (0.3 to 2.6$)$ \\
\hline Dual users $\ddagger$ & 88.1 (79.2 to 97.0$)$ & 60.7 (37.4 to 84.0$)$ & 40.4 (19.3 to 61.5$)$ & 13.5 (4.6 to 22.3 ) \\
\hline \multicolumn{5}{|l|}{ Sex } \\
\hline Female & 53.9 (34.9 to 72.9$)$ & 20.1 (5.1 to 35.1 ) & 9.9 (2.5 to 17.2$)$ & 2.3 (0.7 to 9.9 ) \\
\hline White, non-Hispanic & 48.2 (30.7 to 65.8$)$ & 16.8 (4.8 to 28.8 ) & 7.8 (2.2 to 13.4$)$ & $1.8(0.7$ to 3.0$)$ \\
\hline Other & $61.6(33.3$ to 89.9$)$ & 26.8 (4.9 to 48.6 ) & $13.8(1.6$ to 26.0$)$ & 3.4 (0.4 to 6.5$)$ \\
\hline \multicolumn{5}{|l|}{ Household income } \\
\hline Under $\$ 30000$ ) & 47.0 (27.7 to 66.3$)$ & 16.1 (3.5 to 28.6 ) & 7.5 (1.7 to 13.4$)$ & 1.7 (0.5 to 7.5$)$ \\
\hline$\$ 30000$ and above & 57.6 (37.7 to 77.6$)$ & 23.2 (6.6 to 39.7 ) & $11.4(2.9$ to 19.9$)$ & 2.7 (0.8 to 4.7$)$ \\
\hline $20 \%$ decrease & 51.1 (34.4 to 67.8$)$ & 18.6 (6.2 to 31.0$)$ & 8.8 (2.8 to 14.8$)$ & $2.0(0.8$ to 3.3$)$ \\
\hline
\end{tabular}

${ }^{*}$ Data represent proportions and $95 \%$ Cls based on Monte Carlo analyses with 5000 repetitions.

tSingle users are defined as individuals who engaged in either WTS or cigarette smoking in the past 30 days.

‡Dual users are defined as individuals who engaged in both WTS and cigarette smoking in the past 30 days.

$\S$ Race and ethnic groups were self-reported; the category 'Other' includes black, non-Hispanic, Hispanic and multiracial.

their particular population of interest, were able to categorise WTS behaviours more finely. Finally, our model defined toxicant load using smoke volume, tar, carbon monoxide and nicotine, whereas the prior model quantified toxicant load derived from WTS and cigarettes using a more extensive decomposition of carcinogens specifically. ${ }^{33}$

It is interesting to note that, despite these differences in methodology, the results from both studies are quite consistent, which attests to the robustness of results of both the current and the prior study. The one exception, however, came with regard to carbon monoxide: while Jawad et al found that as much as 73\% of carbon monoxide exposure could be attributed to waterpipes, our figure of about $10 \%$ was much lower. One possible explanation for this difference is that Jawad focused on youth ages 13-15 years in the Eastern Mediterranean Region, whereas we used a nationally representative US sample of young adults ages 18-30 years. Because waterpipe use has increased in the USA even in the past several years since these data were collected in $2013,{ }^{1011}$ it is possible that the proportion of carbon monoxide attributed to waterpipes in the USA may increase over time.

Jawad and Roderick ${ }^{33}$ accounted for sharing of bowls by dividing the amount of estimated toxicant by the number of individuals sharing, which we did not do. However, new research from Ramôa et $\mathrm{al}^{40}$ suggests that when individuals share a bowl—compared with smoking alone-it is unclear to what extent they may be exposed to more or less toxicant. For example, in that study, singletons were exposed to $1.67 \mathrm{mg}$ of nicotine per waterpipe, while each member of a dyad was exposed to $1.31 \mathrm{mg}(2.63 \mathrm{mg}$ for both individuals combined). However, these findings suggest that exposure to individuals in dyads was higher than would be expected based on simple division; if those smoking in dyads are exposed to half of the nicotine of those smoking in singletons, we would expect $0.84 \mathrm{mg}$ of exposure, not $1.31 \mathrm{mg}$ of exposure. In addition, other results from the Ramôa et al's study actually suggest that individuals may be exposed to more of certain toxicants when they smoke in dyads versus singletons. For example, plasma nicotine was actually greater among those smoking in dyads versus singletons (14.9 $\mathrm{mL}$ vs $10.0 \mathrm{ng} / \mathrm{mL}$ ). ${ }^{40}$ The explanation for this seemingly counterintuitive result is that, when individuals share, the coals remain hot throughout the session, releasing relatively more toxicant. Therefore, because of the multifaceted results of the Ramôa et al's study, it will be valuable to continue to study implications of waterpipe sharing for modelling of total exposure.

While toxicant load comparisons are often made between one WTS session and a single cigarette, the volume of smoke inhaled during one WTS session is substantially higher than a single cigarette. Smoking topography studies suggest that smoking one cigarette involves about 10-12 puffs of $50 \mathrm{~mL}$ each, while smoking one 45-60 min hookah session can involve 100 inhalations of about $500 \mathrm{~mL}$ each per individual. ${ }^{44}$ The effect of cooling the products of combustion with water, flavourings and sweetening all facilitate taking more numerous and deeper puffs. ${ }^{46}$ This amount of total smoke inhalation from just one 45-60 min hookah session is concerning, because smoke contains many different potentially harmful combustion products. However, because the smoke from WTS is likely less concentrated than smoke from a cigarette, the practicality of this comparison is uncertain.

Compared with the other toxicants, the proportion of nicotine coming from waterpipes was lower. Nevertheless, even small exposures to nicotine have been associated with the development of addiction, especially in young people. ${ }^{28}$ Additionally, initial use of waterpipe tobacco has been associated with subsequent transition to cigarette smoking. ${ }^{47}$ Finally, while inhaled nicotine concentrations have been found to be relatively low, ${ }^{20}$ in vivo nicotine and cotinine levels have been relatively higher. ${ }^{48} 49$ Thus, even these relatively small proportions of inhaled nicotine attributable to WTS are of concern. It may be valuable for future studies-once sufficient data are available- to examine in vivo nicotine associated with WTS use. Similarly, when more data are available, it will be valuable for future studies to assess other specific toxicants such as heavy metals and polycyclic aromatic hydrocarbons, for which there were insufficient data at this point. ${ }^{20}$ 
These findings suggest that important modifications in tobacco surveillance and prevention programmes are warranted. For example, although some large-scale studies such as the National College Health Assessment and the Monitoring the Future Study recently added items assessing WTS, others have not yet included WTS items. In particular, the recently released 2017 Youth Risk Behavior Surveillance Survey System Questionnaire asks about use of alternative nicotine and tobacco products such as chewing tobacco and electronic cigarettes, but it does not address WTS. Similarly, it will be valuable to update prevention curricula $^{50}$ and practice guidelines for cessation ${ }^{51}$ targeted at youth and young adults in the area of tobacco control, as they are often designed based on literature that focuses on cigarette smoking. 5253

Continued policy reform will be valuable for prevention of WTS. ${ }^{54-56}$ For example, while national laws ban flavouring of cigarettes, these laws do not ban flavouring of shisha, the special form of tobacco used in a waterpipe. Thus, waterpipe users can consume tobacco in flavours such as chocolate and cotton candy, which is particularly relevant for efforts to reduce initiation among teens and young adults; $89 \%$ of adolescents who use WTS use flavoured tobacco. ${ }^{57}$ While the Food and Drug Administration recently finalised a rule extending its authority to include the regulation of WTS, there are no current plans to change policy related to flavourings. ${ }^{58}$ Several Canadian provinces have banned flavoured tobacco products, targeting cigarettes and cigars, but not WTS tobacco. ${ }^{59}$ It will be important to continue to develop and implement improved policies that dissuade use of and exposure to all types of tobacco.

\section{Limitations}

To conduct this analysis, we relied on meta-analytic data comparing toxicant exposures originating from waterpipes and cigarettes. While meta-analysis provides more robust estimates than a single study, limitations of that former study could affect our findings. For example, the meta-analysis used in this study included only those studies published as of April 2013; however, studies published since then either would not have met inclusion criteria or have had results consistent with earlier studies. ${ }^{6061}$ Additionally, the majority of studies measured WTS from a single user, therefore not capturing the effects of sharing or more realistic scenarios. ${ }^{20}$ However, a recent study suggests that the influence of sharing on toxicant load is unclear. ${ }^{40}$ Similarly, participants likely experienced variation in WTS session length. However, we attempted to address this variation by conducting sensitivity analyses the accounted for both increases and decreases in bowls consumed.

A third limitation is that we only considered cigarettes and waterpipes in our analysis and did not also estimate exposure to inhaled toxicants from cigars or e-cigarettes. While currently estimates of toxicant exposure from these other forms of tobacco and nicotine use are scant or conflicting, ${ }^{62-64}$ future research studies should include other forms of tobacco and nicotine when calculating population-level exposure to obtain a more comprehensive estimate. Similarly, it may be valuable for future studies to include herbal waterpipe use, which can be associated with significant toxicant exposure ${ }^{5}$; because we focused only on waterpipe use with tobacco, we may have underestimated total exposures.

The Monte Carlo analyses produced relatively large CIs around our toxicant proportions, which may be due to issues with model precision or variation in our population. However, even considering the CIs, the estimates still provide data of value when considering possible intervention and/or future surveillance. Future studies validating our model will be beneficial to assess stability and precision.

Because our primary data were collected in the spring of 2013, responses may overestimate or underestimate WTS use throughout the calendar year. ${ }^{17}$ However, we conducted several sets of sensitivity analyses varying consumption to account for potential bias in our data collection. It may prove valuable to validate our model in future studies, for example, using data from other times during the year.

\section{CONCLUSION}

Our population-level analysis of a nationally representative cohort of young US adults found that when waterpipes and cigarettes were directly compared, WTS accounted for more than half of the tobacco smoke volume exposure. This was true despite the fact that many WTS users tend to smoke relatively infrequently. Toxicant exposures to tar, carbon monoxide and nicotine were lower, yet substantial, for WTS alone compared with WTS and cigarette smoking. Therefore, it is imperative that public health and policy interventions to reduce tobacco smoking in young US adults explicitly address the substantial WTS toxicant exposure among young adults.

\section{What this paper adds}

- In the USA, waterpipe tobacco smoking (WTS) rates are increasing and cigarette smoking rates are decreasing, especially among young adults.

- Although even a single WTS session is associated with exposure to high levels of toxicants, use is often intermittent compared with cigarette smoking.

- The relative contributions of these two forms of tobacco use to population-level total toxicant load are unknown.

- When we combined meta-analytic estimates of toxicant loads from a single WTS session and from a single cigarette with nationally representative estimates of past 30-day use, $54.9 \%$ (95\% Cl $37.5 \%$ to $72.2 \%$ ) of smoke volume consumed by adults aged $18-30$ years was attributed to WTS.

- The proportions of tar, carbon monoxide and nicotine attributable to WTS were $20.8 \%$ (95\% Cl $6.5 \%$ to $35.2 \%$ ), $10.3 \%(95 \% \mathrm{Cl} 3.3 \%$ to $17.3 \%)$ and $2.4 \%(95 \% \mathrm{Cl} 0.9 \%$ to $3.8 \%)$, respectively.

Contributors BAP conceived of the study and wrote the majority of the first draft. BAP, AS, MSR, and MKM conducted analyses. JES, MCT and JBC wrote sections of the initial draft. AEJ and MJF provided supervision. All authors edited the manuscript for important intellectual content. All authors approved the final version.

Funding The study was funded by National Cancer Institute grant R01-CA140150. Competing interests None declared.

Patient consent Not required.

Ethics approval This study was approved by the University of Pittsburgh Institutional Review Board.

Provenance and peer review Not commissioned; externally peer reviewed. Data sharing statement Data from this study are available upon request.

(C) Article author(s) (or their employer(s) unless otherwise stated in the text of the article) 2019. All rights reserved. No commercial use is permitted unless otherwise expressly granted.

\section{REFERENCES}

1 Jawad M, Lee JT, Millett C. Waterpipe tobacco smoking prevalence and correlates in 25 Eastern Mediterranean and Eastern European Countries: cross-sectional analysis of the Global Youth Tobacco Survey. Nicotine Tob Res 2016;18:395-402. 
2 Martinasek MP, McDermott RJ, Martini L. Waterpipe (hookah) tobacco smoking among youth. Curr Probl Pediatr Adolesc Health Care 2011;41:34-57.

3 Soneji S, Sargent J, Tanski S. Multiple tobacco product use among US adolescents and young adults. Tob Control 2016:25:174-80.

4 Minaker LM, Shuh A, Burkhalter RJ, et al. Hookah use prevalence, predictors, and perceptions among Canadian youth: findings from the 2012/2013 Youth Smoking Survey. Cancer Causes Control 2015;26:831-8.

5 Shihadeh A, Salman R, Jaroudi E, et al. Does switching to a tobacco-free waterpipe product reduce toxicant intake? A crossover study comparing $\mathrm{CO}, \mathrm{NO}, \mathrm{PAH}$, volatile aldehydes, "tar" and nicotine yields. Food Chem Toxicol 2012;50:1494-8.

6 Heinz AJ, Giedgowd GE, Crane NA, et al. A comprehensive examination of hookah smoking in college students: use patterns and contexts, social norms and attitudes, harm perception, psychological correlates and co-occurring substance use. Addict Behav 2013;38:2751-60.

7 Akl EA, Jawad M, Lam WY, et al. Motives, beliefs and attitudes towards waterpipe tobacco smoking: a systematic review. Harm Reduct J 2013;10:12-20.

8 Martinasek MP, Gibson-Young LM, Davis JN, et al. Waterpipe tobacco smoking impact on public health: implications for policy. Risk Manag Healthc Policy 2015;8:121-9.

9 Jawad M, El Kadi L, Mugharbil S, et al. Waterpipe tobacco smoking legislation and policy enactment: a global analysis. Tob Control 2015;24:i60-i65.

10 Sidani JE, Shensa A, Naidu MR, et al. Initiation, progression, and sustained waterpipe use: a nationally representative longitudinal study of U.S. young adults. Cancer Epidemiol Biomarkers Prev 2017;26:748-55.

11 Sidani JE, Shensa A, Shiffman S, et al. Behavioral associations with waterpipe tobacco smoking dependence among US young adults. Addiction 2016;111:351-9.

12 Miech RA, Johnston LD, O'Malley PM, et al. Monitoring the Future national survey results on drug use, 1975-2015: Volume I, Secondary school students. Ann Arbor, MI, 2016. http://www.monitoringthefuture.org//pubs/monographs/mtf-vol1_2015.pdf

13 Primack BA, Freedman-Doan P, Sidani JE, et al. Sustained waterpipe tobacco smoking and trends over time. Am J Prev Med 2015;49:859-67.

14 Villanti AC, Cobb CO, Cohn AM, et al. Correlates of hookah use and predictors of hookah trial in U.S. young adults. Am J Prev Med 2015;48:742-6.

15 Primack BA, Sidani J, Agarwal AA, et al. Prevalence of and associations with waterpipe tobacco smoking among U.S. university students. Ann Behav Med 2008;36:81-6.

16 Sidani JE, Shensa A, Barnett TE, et al. Knowledge, attitudes, and normative beliefs as predictors of hookah smoking initiation: a longitudinal study of university students. Nicotine Tob Res 2014;16:647-54.

17 Fielder RL, Carey KB, Carey MP. Prevalence, frequency, and initiation of hookah tobacco smoking among first-year female college students: a one-year longitudinal study. Addict Behav 2012;37:221-4.

18 Ward KD, Vander Weg MW, Relyea G, et al. Waterpipe smoking among American military recruits. Prev Med 2006;43:92-7.

19 Aljarrah K, Ababneh ZQ, Al-Delaimy WK. Perceptions of hookah smoking harmfulness: predictors and characteristics among current hookah users. Tob Induc Dis 2009;5:16.

20 Primack BA, Carroll MV, Weiss PM, et al. Systematic review and meta-analysis of inhaled toxicants from waterpipe and cigarette smoking. Public Health Rep 2016:131:76-85.

21 Shihadeh A, Saleh R. Polycyclic aromatic hydrocarbons, carbon monoxide, "tar", and nicotine in the mainstream smoke aerosol of the narghile water pipe. Food Chem Toxicol 2005;43:655-61.

22 World Health Organization. TobReg advisory note: waterpipe tobacco smoking: health effects. Research needs and recommended actions by regulators. Geneva, Switzerland, 2005.

23 Cobb CO, Sahmarani K, Eissenberg T, et al. Acute toxicant exposure and cardiac autonomic dysfunction from smoking a single narghile waterpipe with tobacco and with a "healthy" tobacco-free alternative. Toxicol Lett 2012;215:70-5.

24 Al Suwaidi J, Zubaid M, El-Menyar AA, et al. Prevalence and outcome of cigarette and waterpipe smoking among patients with acute coronary syndrome in six MiddleEastern countries. Eur J Prev Cardiol 2012;19:118-25.

25 Akl EA, Gaddam S, Gunukula SK, et al. The effects of waterpipe tobacco smoking on health outcomes: a systematic review. Int J Epidemiol 2010;39:834-57.

26 Shaikh RB, Vijayaraghavan N, Sulaiman AS, et al. The acute effects of waterpipe smoking on the cardiovascular and respiratory systems. J Prev Med Hyg 2008;49:101-7.

27 El-Zaatari ZM, Chami HA, Zaatari GS. Health effects associated with waterpipe smoking. Tob Control 2015;24(Suppl 1):i31-i43.

28 Bahelah R, DiFranza JR, Fouad FM, et al. Early symptoms of nicotine dependence among adolescent waterpipe smokers. Tob Control 2016;25:e127-e134.

29 Smith-Simone S, Maziak W, Ward KD, et al. Waterpipe tobacco smoking: knowledge, attitudes, beliefs, and behavior in two U.S. samples. Nicotine Tob Res 2008;10:393-8.

30 Eissenberg T, Ward KD, Smith-Simone $S$, et al. Waterpipe tobacco smoking on a U.S. college campus: prevalence and correlates. J Adolesc Heal 2008;42:526-9.

31 Primack BA, Walsh M, Bryce $C$, et al. Water-pipe tobacco smoking among middle and high school students in Arizona. Pediatrics 2009;123:e282-e288.

32 Asfar T, Ward KD, Eissenberg T, et al. Comparison of patterns of use, beliefs, and attitudes related to waterpipe between beginning and established smokers. BMC Public Health 2005:5:19.
33 Jawad M, Roderick P. Integrating the impact of cigarette and waterpipe tobacco use among adolescents in the Eastern Mediterranean Region: a cross-sectional, population-level model of toxicant exposure. Tob Control 2017;26.

34 Fielder RL, Carey KB, Carey MP. Hookah, cigarette, and marijuana use: a prospective study of smoking behaviors among first-year college women. Addict Behav 2013;38:2729-35.

35 Salloum RG, Haider MR, Barnett TE, et al. Waterpipe tobacco smoking and susceptibility to cigarette smoking among young adults in the United States, 2012-2013. Prev Chronic Dis 2016;13:150505.

36 GfK KnowledgePanel. KnowledgePanel design summary. 2013 http://www. webcitation.org/6ajEW05mb (accessed 8 Jan 2018).

37 Griffiths MA, Harmon TR, Gilly MC. Hubble bubble trouble: the need for education about and regulation of hookah smoking. Journal of Public Policy \& Marketing 2011;30:119-32.

38 Robinson J, Wang B, Jackson K, et al. Characteristics of Hookah Tobacco Smoking Sessions and Correlates of Use Frequency among US Adults: Findings from Wave 1 of the Population Assessment of Tobacco and Health (PATH) Study. Nicotine Tob Res 2017; 10 .

39 Jacob P, Abu Raddaha AH, Dempsey D, et al. Comparison of nicotine and carcinogen exposure with water pipe and cigarette smoking. Cancer Epidemiol Biomarkers Prev 2013;22:765-72

40 Ramôa CP, Shihadeh A, Salman R, et al. Group waterpipe tobacco smoking increases smoke toxicant concentration. Nicotine Tob Res 2016;18:770-6.

41 Kabir E, Kim KH, Ahn JW, et al. Barbecue charcoal combustion as a potential source of aromatic volatile organic compounds and carbonyls. J Hazard Mater 2010;174:492-9.

42 Elsayed Y, Dalibalta S, Abu-Farha N. Chemical analysis and potential health risks of hookah charcoal. Sci Total Environ 2016;569-570:262-8.

43 Microsoft. Microsoft Excel. 2010.

44 Eissenberg T, Shihadeh A. Waterpipe tobacco and cigarette smoking: direct comparison of toxicant exposure. Am J Prev Med 2009;37:518-23.

45 Maziak W, Rastam S, Ibrahim I, et al. CO exposure, puff topography, and subjective effects in waterpipe tobacco smokers. Nicotine Tob Res 2009;11:806-11.

46 American Lung Association. An emerging deadly trend: Waterpipe tobacco use. Chicago, IL 2007 http://www.lungusa2.org/embargo/slati/Trendalert_Waterpipes.pdf

47 Soneji S, Sargent JD, Tanski SE, et al. Associations between initial water pipe tobacco smoking and snus use and subsequent cigarette smoking: results from a longitudinal study of US adolescents and young adults. JAMA Pediatr 2015;169:129-36.

48 Shafagoj YA, Mohammed Fl, Hadidi KA. Hubble-bubble (water pipe) smoking: levels of nicotine and cotinine in plasma, saliva and urine. Int I Clin Pharmacol Ther 2002;40:249-55.

49 Salameh P, Aoun Bacha Z, Waked M. Saliva cotinine and exhaled carbon monoxide in real life waterpipe smokers : A post hoc analysis. Tob Use Insights 2009;2:1-10.

50 Sherman EJ, Primack BA. What works to prevent adolescent smoking? A systematic review of the National Cancer Institute's research-tested intervention programs. J Sch Health 2009;79:391-9.

51 Tobacco Use and Dependence Guideline Panel. Treating tobacco use and dependence. Rockville, MD, 2008. http://www.ncbi.nlm.nih.gov/books/NBK63952/

52 Jawad M, Jawad S, Waziry RK, et al. Interventions for waterpipe tobacco smoking prevention and cessation: a systematic review. Sci Rep 2016;6:25872.

53 Lopez AA, Eissenberg T, Jaafar M, et al. Now is the time to advocate for interventions designed specifically to prevent and control waterpipe tobacco smoking. Addict Behav 2017:66:41-7

54 Islam F, Salloum RG, Nakkash R, et al. Effectiveness of health warnings for waterpipe tobacco smoking among college students. Int J Public Health 2016;61:709-15.

55 Jawad M, El Kadi L, Mugharbil S, et al. Waterpipe tobacco smoking legislation and policy enactment: a global analysis. Tob Control 2015;24 Suppl 1:i60-i65.

56 Primack BA, Hopkins $\mathrm{M}$, Hallett $\mathrm{C}$, et al. US health policy related to hookah tobacco smoking. Am J Public Health 2012;102:e47-e51.

57 Ambrose BK, Day HR, Rostron B, et al. Flavored tobacco product use among us youth aged 12-17 years, 2013-2014. JAMA 2015;314:1871.

58 U.S. Food and Drug Administration. Extending authorities to all tobacco products, including E-Cigarettes, cigars, and hookah. 2016. accessed http://www.fda.gov/ TobaccoProducts/Labeling/RulesRegulationsGuidance/ucm388395.htm

59 Drost P. Provincial ban on flavoured tobacco begins New Year's Day: CBC News, 2015 http://www.webcitation.org/6q2WQFeJX

60 Martinasek MP, Ward KD, Calvanese AV. Change in carbon monoxide exposure among waterpipe bar patrons. Nicotine Tob Res 2014;16:1014-9.

61 Cobb CO, Blank MD, Morlett A, et al. Comparison of puff topography, toxicant exposure, and subjective effects in low- and high-frequency waterpipe users: a double-blind, placebo-control study. Nicotine Tob Res 2015;17:667-74.

62 Farsalinos KE, Polosa R. Safety evaluation and risk assessment of electronic cigarettes as tobacco cigarette substitutes: a systematic review. Ther Adv Drug Saf 2014;5:67-86.

63 Goniewicz ML, Knysak J, Gawron M, et al. Levels of selected carcinogens and toxicants in vapour from electronic cigarettes. Tob Control 2014;23:133-9.

64 Farsalinos KE, Spyrou A, Tsimopoulou K, et al. Nicotine absorption from electronic cigarette use: comparison between first and new-generation devices. Sci Rep 2014;4:4133. 